\title{
Impact of marketing communication mix on business results of SMEs
}

\author{
Gergana Todorova $^{1 *}$, and Georgi Zhelyazkov ${ }^{1}$ \\ ${ }^{1}$ Department of Industrial business and entrepreneurship, Faculty of Economics, Trakia University, \\ 6000 Stara Zagora, Bulgaria
}

\begin{abstract}
Marketing communications show a favorable impact on all aspects of the company's activities. They play an essential role in shaping the final economic results. The purpose of the research is to study the effects of elements for marketing communication mix on the business results of selected small and medium enterprises in Stara Zagora district, Bulgaria. The collection of primary data has been developed and disseminated to the owners/managers of SME's survey. The research uses a descriptive and casual research approach to identify the impact of individual communication elements - advertising, sales promotion, and direct marketing on some financial parameters, such as the profit, sales, and profitability of the companies. The result shows statistical significance between advertising, sales promotion, and financial indicators: profit and net sales revenue. Recommendations were made to the SME managers regarding the use of promotional activities, using communication channels to inform and keep up to date customers, the effectiveness of the types of media, and more.
\end{abstract}

\section{Introduction}

Marketing communications show a favorable impact on all aspects of the SME's activities. They play an essential role in shaping the final economic results. They are seen as the exchange of processes, creating an additional context effect on the relationship between the organization and its customers. The communication mix consists of marketing communication tools that represent a brand and organize their audiences to achieve business success [1]. These instruments have a rapid and direct impact on the target market.

Competition motivates companies to look for innovative ways to inform their customers, not only to gain market share but also to keep what they already have. By making investments in marketing communication tools: advertising, public relations, sales promotion, personal sales, and direct marketing, companies are moving ahead of their competitors and improving their efficiency. The purpose of the elements of the communication mix is to make the organization and its products well known and to position the brand in the minds of consumers to achieve the best result for the company. Using the variety of tools of the communication mix is a differentiating factor between successful companies that control large market shares and play a key role in organizations.

* Corresponding author: gerganatodorova@ @abv.bg 


\section{Marketing communications}

Marketing communications are the fourth main element of the marketing mix with which the company seeks to serve its target markets. Their goal is to make the organization and its products known to customers, as well as to keep the image of the organization in the minds of customers. In addition, marketing communications help the firm to provoke favorable reactions from customers [2]. They are a major factor in the process of building customer trust for an organization and can be seen as an exchange of processes to create an extraordinary contextual effect on the relationship between the organization and its customers. Events around marketing communications, and the development of digital technologies, define them as audience-focused, business process of strategic management of stakeholders, content, channels, and results of brand communication programs [3]. Marketing communications cover a set of strategies, techniques, and tactics for achieving business goals aimed at current and potential customers, using the tools of the communication mix.

The communication mix is a combination of marketing communication tools that help reach target customers as well as persuade them to buy [4]. The tools of the communication mix contribute to building and maintaining brands by informing, updating, persuading, and reminding customers about the brand's products/goods or services [5]. A huge variety of elements of the communication mix continue to be revealed in recent years [6], but the five main controllable marketing communication tools are advertising, sales promotion, personal sales, public relations, and direct marketing [7-8].

Figure 1 is a simplified diagram showing how marketing elements are marketed and activities can be integrated. The biggest crime shows as five interconnected marketing communication elements. The individual elements, depicted in different colored circles, contain a variety of communication activities.

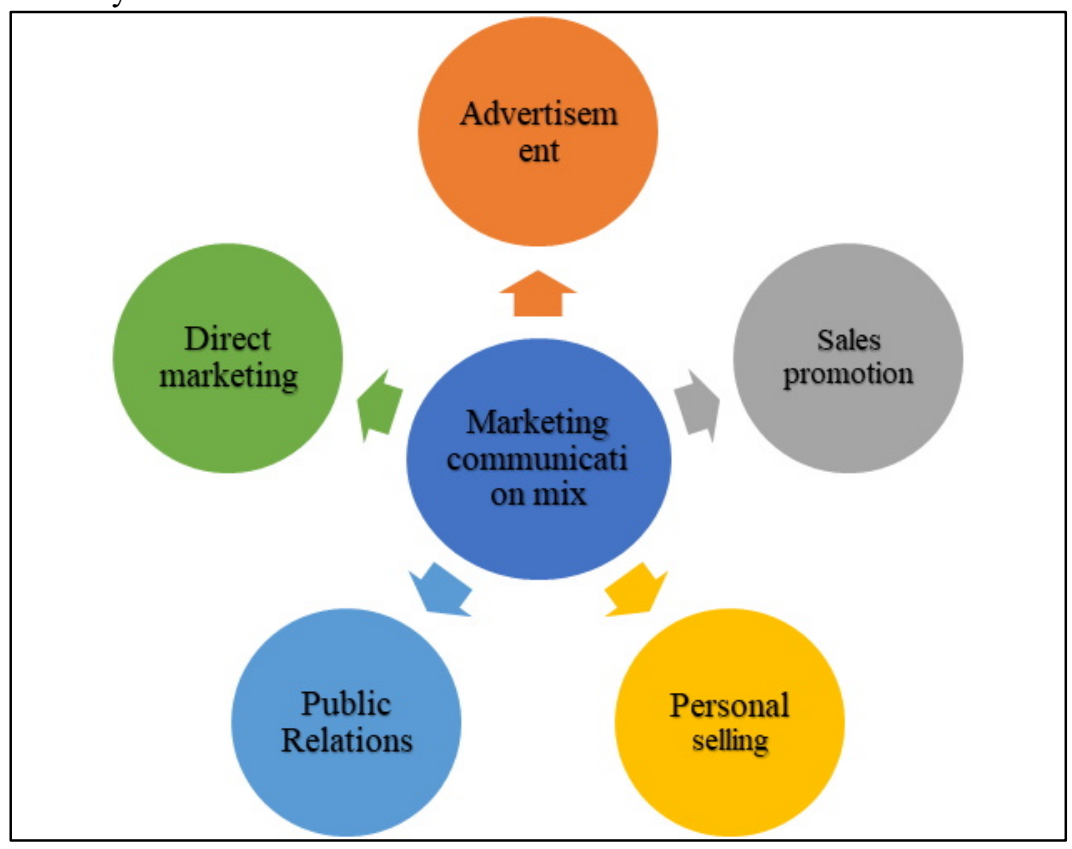

Fig. 1. Marketing communication mix

\section{Measuring SME`s business results}


The dynamics of Bulgaria's GDP growth over the past three years has made a positive contribution to both domestic demand and net exports and ranked our country seventh in the EU in terms of economic growth. This has led to a positive increase in other components embedded in the structure of economic growth, namely household consumption, government and private investment, and exports of goods. The continuing increase in labor demand is accompanied by an increase in the average wage in most of the high-productivity sectors, namely: services, industry, construction, and agriculture. The growth of production in these sectors, accompanied by an increase in jobs and labor productivity, plays a crucial role in the overall economic development and growth of our country in the coming years.

In the dynamics of modern business relations, companies face new challenges in terms of customer requirements, partners, markets, employees, and other contractors. Creating value for the brand, for the product, for the business organization, is becoming an increasingly important task not only for the marketing of companies but also the basis of the overall business planning and development of organizations (9). How to increase the efficiency of marketing efforts in conditions of excessive competition, similar products/products with low diversification/and decreasing advertising efficiency? Practice shows that marketing functions are essential, especially in the relationship with customers and ways to communicate with them. Communications are especially important for business because they contribute to the understanding of customers and influence their behavior. Companies that use all possible communication channels, emphasizing the same content, but modified to the communication channel and the target audience, strive for effective management, strategic business development, and sustainable corporate growth.

Marketing seeks to increase sales and achieve them by increasing product diversity, geographical expansion, various types of communication tools and techniques. The most important aspects of successful marketing are the forms of consumer engagement and the digital connection with them, which grows into a fascinating and emotional experience at the point of sale.

\section{Methods}

This study aims to determine the effect that the communication elements advertising, sales promotion, and direct marketing have on some aspects of company activity such as sales, profit, the profitability of companies in the Trade and Manufacturing sectors in the Stara Zagora region, Bulgaria. The survey measures the effect of the marketing communication mix on sales and profit results, the sample includes owners and managers of commercial and manufacturing enterprises in the region as respondents, as they are the relevant source of information on marketing communications that companies use in their communication policy. The survey was provided to randomly selected respondents from both sectors in the Stara Zagora region. Primary data were collected using the survey. Data on dependent variable net sales, profits, and profitability revenues were purchased from official sources. The study found that all independent variables, which were advertising, sales promotion, and direct marketing, were rated by surveyed managers and owners with good ratings. The study interprets the findings in line with the theories supporting the study, as well as the results of other previous studies, and notes that the results are consistent with the theory and previous studies.

\section{Dependent variables}

Dependent variables in the correlation equation include the company's sales and its profit. Using each of the above variables has its logic. Brand sales are the dependent variable that is 
preferred when the purpose of the analysis is to establish the immediate and short-term effects of the promotion. The profit is used in case of assessment of long-term effects, ie. in cases where the strategic role of incentives in the communication mix is analyzed. The company's sales as a dependent variable are suitable for establishing the influence and significance of the various characteristics of the promotion (depth of promotion, advertising support, merchant support). To the extent that profit and loss analysis requires sales data, brand / firm sales as a dependent variable are always relevant. Several studies show that the promotion of a particular brand has an impact on sales of the entire product category - the so-called. category extension effect. The decision to include profitability as a dependent variable in the regression model is more strategic.

Profit is an economic category of commodity production and a synthetic quality indicator for evaluating the performance of the industrial enterprise. By its economic nature, the profit is obtained in the phase of production of the products and is manifested in the sphere of circulation.

The profit of the enterprise expresses primarily economic relations that arise between it (the enterprise) and society (the state with its institutions and other producers) through the state budget. They arise in connection with the functioning of industrial companies.

Profit is used as a value indicator to characterize the overall organizational, productiontechnological, and management activities of industrial companies. This is because it reflects all aspects of the company's activities. This is the main reason why profit participates as an indicator for measuring the efficiency of companies.

Economic theory and practice have necessitated the use of profit as an economic lever to influence and stimulate production and trade. Therefore, when analyzing the efficiency of the companies, along with the profit, it is appropriate to use other quantitative and qualitative indicators.

Profitability is a summary indicator because it reflects the overall efficiency of the corporation for a certain period. From the investor's point of view, profitability embodies the basis of his interests, namely the company's ability to produce money. Since in practice the degree of profitability depends on how much the company will reinvest and pay in the form of dividends ultimately on the level of the indicator largely depends on the degree of growth of the company itself and its market valuations. These indicators are calculated as the ratio between the different types of profits and sales revenues. The financial meaning of the obtained result is the share of the profit from the total amount of the sales revenues. The study of the relationship and dependencies between the indicators is extremely important for concluding the profitability and effect of the company.

\section{Results}

The study met the four pre-set goals, namely, to confirm (or reject) the existence of a positive relationship between evaluations of the elements of the communication mix (advertising, sales promotion, direct marketing) and the above aspects of the company's activities (net profit, net sales revenue, profitability):

Ho: Advertising as an element of the communication mix has a positive impact on some aspects of the company's activities.

$\mathrm{Ho}^{1}$ : The promotion of sales as an element of the communication mix has a positive impact on some aspects of the company's activities.

$\mathrm{Ho}^{2}$ : Direct marketing as an element of the communication mix has a positive impact on some aspects of the company's activities.

H1: The various elements of the communication mix do not have a positive impact on some aspects of the company's activities. 


\subsection{Comparative analysis of statistically significant differences between the assessments of the elements by sectors}

Using a one-sample t-test, we compared the two sectors of the evaluations for advertising, sales promotion, and direct marketing for the two years studied to see if there were statistically significant differences in the use of the elements in the two sectors. The results are expressed in the following fig. 1-2 and represent the average estimates of the two sectors Trade and Production sector in the Stara Zagora region on the elements of the communication mix advertising, sales promotion, and direct marketing.

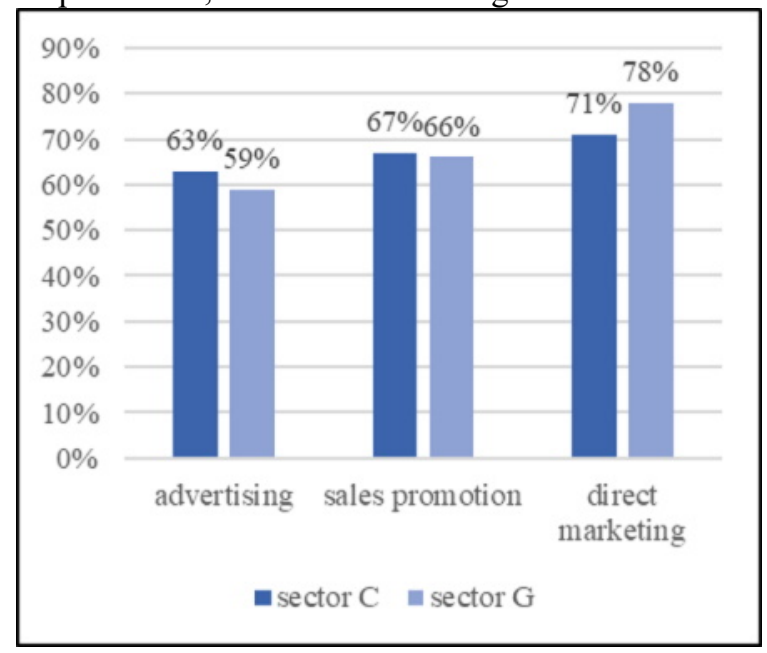

Fig. 1. Distribution of the average ratings of the advertising, sales promotion and direct marketing by sectors for 2015

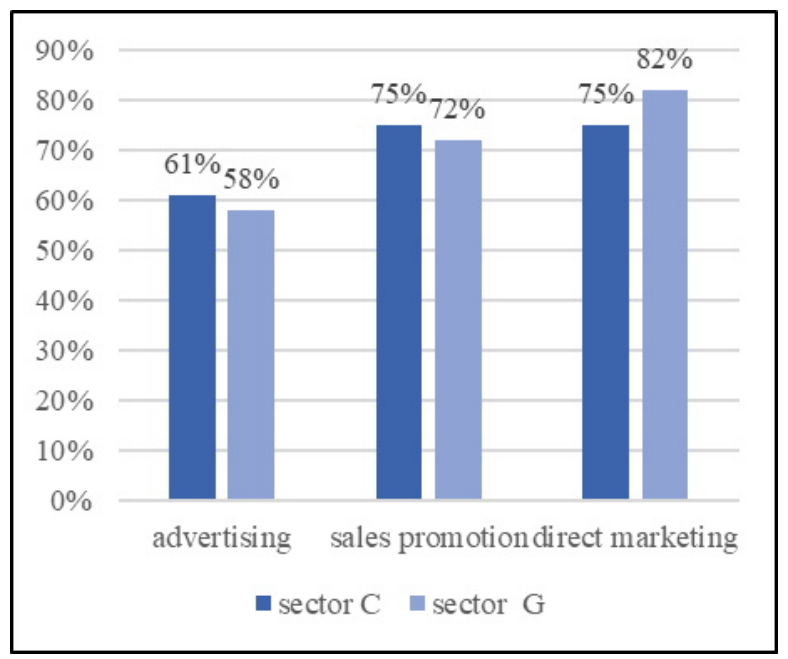

Fig. 2. Distribution of the average ratings of the advertising, sales promotion and direct marketing by sectors for 2016

The obtained results show that the companies from sector $\mathrm{C}$ evaluate the advertising with average grades of 4.44 and 4.25 respectively for the two surveyed years or about $63 \%$ of the surveyed companies. Thus, the ratings are higher than the companies in sector $\mathrm{G}(59 \%)$, which leave in the background the use of the element of advertising as a form of product presentation, giving it lower ratings, respectively 4.13 and 4.06. As can be seen from the 
graphs, estimates for the sales promotion element are approximately the same for the two sectors, respectively 65 to $67 \%$ for 2015 . and 75 to $72 \%$ for 2016 , indicating that both sectors are taking advantage of the element's various instruments to offer additional incentives to increase sales. The results of the tests show that companies in the Trade sector (82\%) rely on direct marketing as a means of sale with average scores of 5.44 for 2015. and 5.75 for 2016. This can be explained by the use of direct sales by catalog or through advertising leaflets and brochures, as well as other new and attractive direct marketing tools such as telemarketing, email, direct mail, social networks, etc., containing the potential for brand development. and generating sales.

\subsection{Analysis of the degree of interdependence between the elements of the communication mix and the activity of the company}

A total of 9 interactions were studied - 3 elements of the communication mix advertising, sales promotion, and direct marketing on 3 aspects of the company's activity - net sales revenue, profit, and profitability. The strength of this effect was analyzed with the nonparametric Spearman coefficient. Using a social science statistic calculator, we calculate the Spearman coefficient for each of the rank-scaled pairs. The results are presented in the table as follows:

Table 1 Rank correlation

\begin{tabular}{|c|c|c|c|c|}
\hline Researched dependencies & $\begin{array}{c}\text { Spearman } \\
\text { coefficient } \mathbf{R}\end{array}$ & $\mathbf{N}$ : & P value & Significance \\
\hline Advertising / net sales revenue & 0.44717 & 64 & 0.00021 & Statically significant \\
\hline $\begin{array}{c}\text { Sales promotion - net sales } \\
\text { revenue }\end{array}$ & 0.26322 & 64 & 0.0356 & Statically significant \\
\hline $\begin{array}{c}\text { Direct marketing - net sales } \\
\text { revenue }\end{array}$ & 0.00432 & 64 & 0.97295 & $\begin{array}{c}\text { Not statistically } \\
\text { significant }\end{array}$ \\
\hline Advertising - net profit & 0.26881 & 64 & 0.03173 & Statically significant \\
\hline Sales promotion - net profit & 0.26157 & 64 & 0.03681 & Statically significant \\
\hline Direct marketing - net profit & 0.04246 & 64 & 0,73903 & $\begin{array}{c}\text { Not statistically } \\
\text { significant }\end{array}$ \\
\hline $\begin{array}{c}\text { Advertising - coefficient of } \\
\text { profitability of sales revenue }\end{array}$ & 0.03728 & 64 & 0.76991 & $\begin{array}{c}\text { Not statistically } \\
\text { significant }\end{array}$ \\
\hline $\begin{array}{c}\text { Sales promotion - coefficient of } \\
\text { profitability of sales revenue }\end{array}$ & 0.09086 & 64 & 0.47523 & $\begin{array}{c}\text { Not statistically } \\
\text { significant }\end{array}$ \\
\hline $\begin{array}{c}\text { Direct marketing - coefficient of } \\
\text { profitability of sales revenue }\end{array}$ & 0.00528 & 64 & 0.96699 & $\begin{array}{c}\text { Not statistically } \\
\text { significant }\end{array}$ \\
\hline
\end{tabular}

To form conclusions about the strength of the relationship between the studied quantities, we used the analysis.

Regarding the first aspect of the company's activity - net sales revenues for 2 out of 3 elements of the communication mix, we have a statistically significant relationship. According to the table of t-distribution in a two-way test and a critical level of significance of $0.001<0.05$, it can be stated that there is a statistically significant relationship between the elements of the communication mix and some aspects of the company.

We find a statistically significant relationship between the estimates of the studied element advertising and net sales revenue with a value of $R$ is 0.44717 and the value of two 
queues of $\mathrm{P}$ is 0.00021 . The relationship between the two variables will be considered statistically significant.

In the calculation of the element sales promotion and net sales revenue, the value of $R$ is 0.26322 and the value of the pair of $\mathrm{P}$ is 0.0356 . Under normal distribution, the relationship between the two variables will also be considered statistically significant.

Considering that the relationship between the estimates of the direct marketing element and net sales revenue at a value of $\mathrm{R}$ is 0.00432 and the value of the pair of $\mathrm{P}$ is 0.97295 , the relationship between the two variables would not be considered statistically significant.

Accordingly, we calculate the Spearman coefficient for each of the estimates of the elements and their relationship to the rank-scaled net profit. The results are as follows:

For the element advertising and its relation to the net profit of the companies, the value of $\mathrm{R}$ is 0.26881 and the value of the pair of $\mathrm{P}$ is 0.03173 . The relationship between the two variables will be considered statistically significant.

For the sales promotion element, the value of $\mathrm{R}$ is 0.26157 , respectively, and the value of two queues of $\mathrm{P}$ is 0.03681 . The relationship between the two variables will be considered statistically significant.

And for direct marketing and net profit, the value of $\mathrm{R}$ is 0,04246 , and the value of the pair of $\mathrm{P}$ is 0,73903 . Under normal distribution, the relationship between the two variables would not be considered statistically significant.

We performed the same tests for the return on sales revenue ratio in $\%$ to examine the relationship with each of the elements of the communication mix, but with values of $\mathrm{R}<0.05$, their relationship would not be considered statistically significant.

The presented empirical study found a statistically significant relationship between advertising, sales promotion, and financial indicators: profit and net sales revenue, found by other authors $[10 ; 11]$. At the same time, companies that are convinced that communication activities can have a positive impact on the company's economic performance realize a higher value of profit. The amount of net profit is a more accurate measure of the efficiency of companies than the amount of net sales revenue. This is because the profit is an expression of the added value, which is the resultant value of the costs incurred. As a function of profit, net sales revenues, which are the second studied financial and economic indicator, but are far from the only factor of profit, ie. it is not uncommon for no statistical relationship to be found between direct marketing as an element of the communication mix and net sales revenue, as is the case with the other two elements of advertising and sales promotion. The reasons can be found in some axiomatic findings and limitations of the conducted empirical research.

For salespeople and managers, the adjusted correlation coefficient is a more reliable indicator of the important "key factors" of their marketing models. In turn, this allows them to develop more effective targeted marketing and communication strategies for their campaigns.

\subsection{Other results of the survey}

In an environment of a highly competitive market, customers are constantly attacked with promotional messages, and only $34.4 \%$ of respondents use promotional activities daily, as shown in fig. 3 below. 


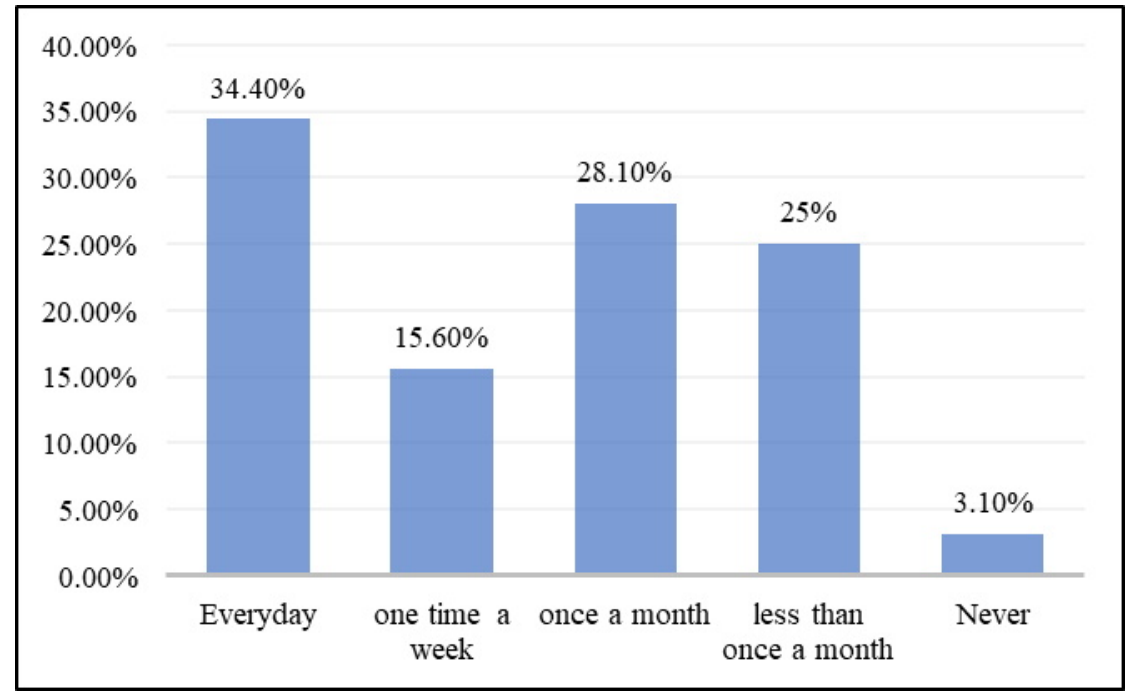

Fig. 3. Frequency of use of promotional activities

Figure 4 shows the percentage of used communication channels through which companies inform their customers about their promotional activities.

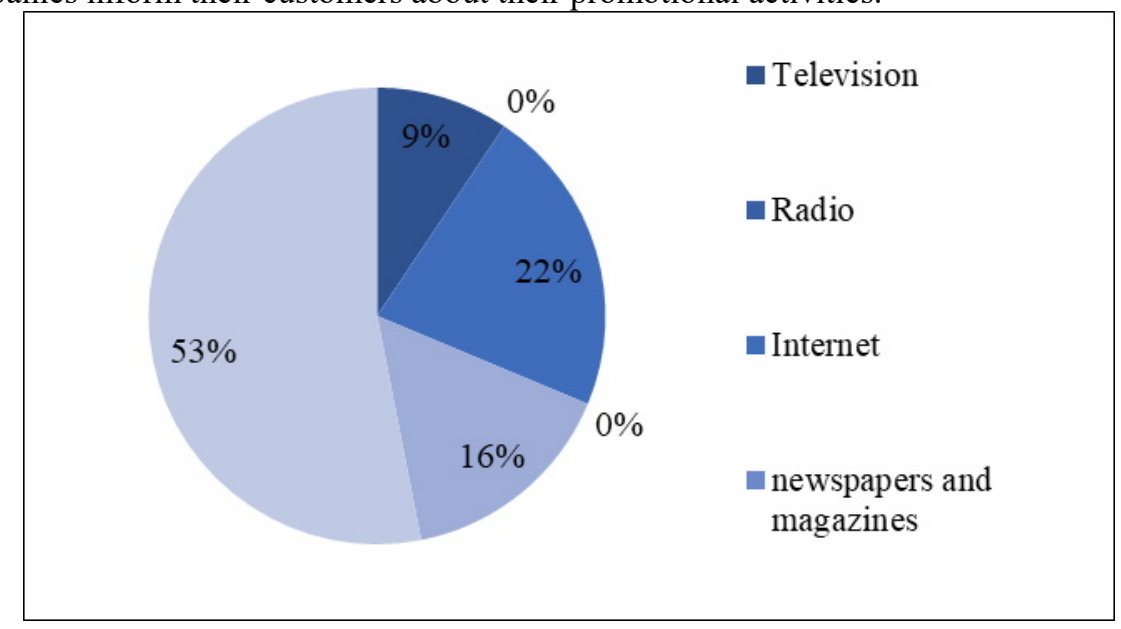

Fig. 4. Percentage of used communication channels

In the surveyed sectors the best, according to the surveyed companies, is the approach through a personal presentation of the product $53.1 \%$, followed by the current direct marketing with a total of $37.5 \%$, respectively the Internet with $21.9 \%$, and messages by email, mail and others. $15.6 \%$.

The assessment of the effectiveness of the types of media in surveying companies is performed on a scale from 1 to 1 to 2 very poorly; 3 plates; 4 neither strong nor weak; 5 strong; 6 very strong; Extremely strong. You can also get interesting results by contacting media research as an environment for communication. Respondents rate television with mixed ratings. This is because a large part of the company operator at the regional level and is not actively used. They are followed by e-mail, with 22 respondents believing that e-mail is also a strong means of communication and direct contact with targeted customers. The catalog as a means of communication between the client and the company is also not inferior and $70 \%$ of respondents rate with grades from 5 to 7 , ie. strongly to off. Radio and 
Newspapers are valued as channels with fading functions - neither strongly nor highly. But they would be suitable for advertising at the local and regional levels. The personal performance of the respondents is evaluated with excl. strong grades. This can be explained by the specifics of the products that companies offer.

The synergy of different channels and means of communication will give more impetus to companies than their competitors in the market. Attacking the customer through the right messages and a combination of communication channels effectively and permanently pushes the brand to the forefront in the minds of consumers and customers. The surveyed companies were asked to give assessments related to the strongest side of their communication policy. To do this, they had to rate the three elements of advertising, sales promotion, and direct marketing by ranking their ratings on a scale from 1 to 3 . The graphs below show the percentage of managers' ratings concerning the strongest side of the communication policy of the company for the considered two years.

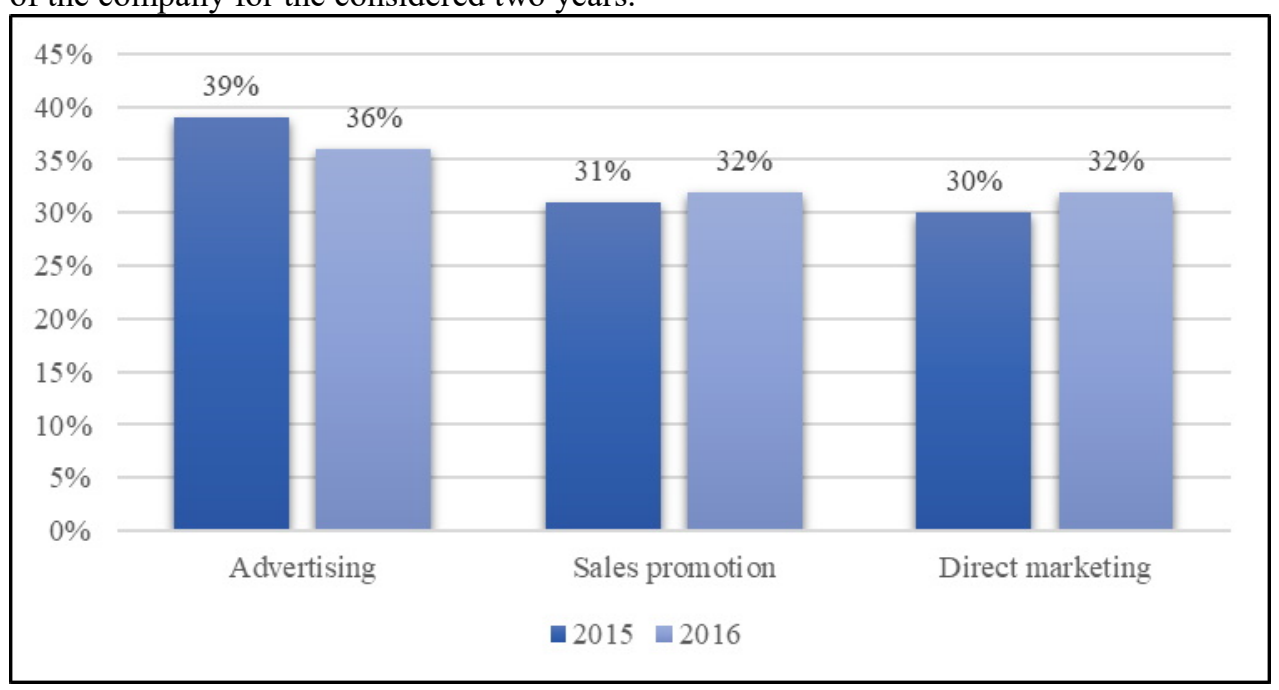

Fig. 5. The strongest side of the company's communication policy for 2015. and 2016

For the two years studied, the companies evaluate the elements of the communication mix with approximately the same values. The surveyed companies define the combination of the used communication elements as a strength of their communication policy in both studied years (the figure above). In addition, the results show that the tool for direct marketing and sales promotion are the most effective tools, and in third place is the tool advertising. Market communication can have a major impact on generation goals if properly implemented, however, it varies depending on the type of product and service to be delivered.

The integration of marketing communications and their elements allows the realization of many business goals and the starting point is the customer. Communication programs combine these forms in different combinations and subordinate them to a single logic, tailored to a specific product, situation, and audience. That is, they are inextricably linked to the marketing mix, carefully coordinating and mutually coordinating its elements. This statement is in line with $62 \%$ of the surveyed companies, and the remaining $34.4 \%$ largely agree.

The combined use of communication tools allows managers to combine them so that they complement each other. The aim is a consistent and logical presentation of the messages in their harmony. All communications of the company must follow a single logic and convey messages sounding in the same key. This increases the overall impact on audiences, and this is useful, especially in low-budget campaigns, because it ensures objective service to the 
advertiser. The communication policy of the company has the task to activate consumer demand by creating and maintaining a favorable image of the communicator, promoting its brand, and purposeful demonstration of the goods and services offered. This policy is implemented through a scientifically based combination of its communication elements. In other words, integrated marketing communications achieve a synergistic effect, concentrating all communications on one image. In the context of integrated marketing communications, the effectiveness of advertising and the company's image can be improved.

The results showed that in the current context the following findings can be made regarding the three elements examined.

$\checkmark \quad$ Advertising plays an important role in the communication policy of companies in the surveyed sectors. The advertising activities are defined as effective and with a positive impact on the considered aspects of the company's activity.

$\checkmark \quad$ Sales promotion is a communication element with an extremely beneficial effect on the company's activities. The effect of promotions is almost instantaneous - by increasing prices, sales increase.

The use of the direct marketing element improves the company's activity. It can create closer and yet more cost-effective relationships with customers in terms of sales, marketing, and customer service.

These conclusions cannot be accepted as universal, as the evaluation was influenced by the subjective evaluation of the managers. Estimates will vary according to the annual profit and turnover of the companies. At the same time, if the use of elements such as frequency and instruments increases, profits and sales will also increase. But the opposite statement is also not excluded - the more sales and profits companies have, the more their managers will increase the use of communication elements. The presented assumption specifies that the higher the profits and sales of the company, respectively the size of the company, the greater the effect of the respective communication elements.

\section{Conclusion}

The elements of the communication mix are an important tool for any organization. Every company should consider how to use and how to take advantage of them in the best way for the company. Especially for manufacturers and retailers, these elements have a particularly important role to play in succeeding in their sales, raising awareness of their products, as well as customer retention.

As a result of the research work, the following conclusions can be drawn:

$\checkmark$ A communication mix is an important tool for introducing products to the market. The meaning of good communication with the client refers to building good relationships with the company or organization. The company or organization must introduce or inform the customer about each of the products or services they offer so that the customer can easily choose and find out about the products themselves.

The results of the study showed that it is possible to measure the impact of communication elements: advertising, sales promotion, and direct marketing on the activities of companies in the Trade and Manufacturing industry

$\checkmark \quad$ If advertising, sales promotion, and direct marketing of the brand focus on profits and sales, there is a possibility that such marketing actions will play a positive role and increase both sales and profits of companies. Also, in the process of allocating marketing budgets to cover individual elements of the communication mix, it is necessary to take into account the potential effects of each element of the mix on building effective communication with customers.

$\checkmark$ Based on the analysis, we can consider that there is a statistically significant relationship between the estimates of the studied element advertising and net sales $(\mathrm{R}=$ 
$0.44717)$, sales promotion and net sales $(\mathrm{R}=0.26322)$, advertising and net profit $(\mathrm{R}=$ $0.26881)$, sales promotion and net profit $(\mathrm{R}=0.26157)$. Concerning the direct marketing element, no statistically significant correlations were found with either net profit or sales revenue. And concerning the coefficient of profitability of sales revenues, no statistically significant relationship was found for any of the elements of the communication mix. Therefore, we can conclude that if management focuses its efforts on attacking customers through constant and targeted communication messages, they can significantly help a competitive company to improve its financial performance, as well as growth and market performance. The correct application of the communication mix will have a significant positive impact on sales, profits, respectively market share and will improve organizational growth in conditions of strong competition.

The importance of the communication mix depends on its positive impact on some aspects of the company's activities. Perceiving the importance of the effect of selected elements of the communication mix on companies' profits and sales, in current situations and competitive markets, helps decision-makers to get more information on how to use selected elements of the mix and to choose the best combination of these elements, which ultimately leads to the profitability of companies. From the management's point of view, profitable communication offers a competitive advantage for the company.

The value of the elements of marketing communications on the effectiveness of the organization is indisputable. Merchants help businesses build a strong corporate identity that shapes the image of the company/brand through the use of tools widely used in the field of communications. In addition, marketers are responsible for managing various stakeholders, in addition to individual clients [12]. The elements of the communication mix enable the management to get to know the market and the potential business directions. This can ultimately affect the decision-making of companies. But most importantly, building healthy relationships and knowing the client's needs is key to any successful business [12]. Therefore, corporate communication at the strategic level of the organization is an integrated framework for the management of overall communications, where marketing communications are an integral part of it [13]. The elements of the communication mix simply allow marketing to serve corporate communication and therefore its contribution should not be overlooked by the overall performance of the organization in the context of corporate communication. This is why the evaluation of marketing communications has become a vital issue in determining the effectiveness of companies. The study of the goals and results of the management of the various elements of marketing communications will create new business opportunities and increase the efficiency of promotional activities, as well as integrated marketing communications in general.

\section{References}

1. C. Fill, Marketing Communications: Contexts, Strategies and Applications, 3rd ed., (Harlow, Financial Times Prentice Hall, 2002)

2. T. Duncan, S. E. Moriarty, J. Mark., 62(2), 1-13 (1998)

3. J. G. Kliatchko, Int. J. Advert., 24(1), 7-34 (2005)

4. Ph. T. Kotler, K. L. Keller, Marketing Management, 14th Ed., (2012)

5. I. Buil, L. De Chernatony, E. Martinez, J. Bus. Res., 66(1), 115-122 (2013)

6. K. L. Keller, J. Mark. Manag., 17(7-8), 819-847 (2001)

7. C. Fill, Simply marketing communications, (Pearson Education, 2006)

8. P. Kotler, G. Armstrong, Principles of Marketing. 14th Ed., (Pearson Education Limited, Essex, England, 2012) 
9. S. Temelkova, Content marketing and business development, in Proceedinhs of International Science Conference devoted to the 20th Anniversary of the Establishment of the Marketing Department at University of Economics, 29-30 June 2017, Varna, Bulgaria, 168-177 (2017)

10. A. Luizov, Evaluation of sales promotions' effects: implementation of two group quasiexperimental design, in Proceedings: Marketing metamorphosis and challenges in the digital age, NBU, Bulgaria, 139-145 (2013), ISBN 978-954-9370-91-1

11. E. Kostadinova, Price promotions - a short-term solution or a long-term problem?, in Proceedinhs of International Science Conference devoted to the 20th Anniversary of the Establishment of the Marketing Department at University of Economics, 29-30 June 2017, Varna, Bulgaria, 390-396 (2017)

12. R. J. Varey, Marketing Communication: An Introduction to Contemporary Issues, (Florence, KY, USA, Routledge, 2001)

13. J. Cornelissen, Corporate Communication. A Guide to Theory and Practice, (SAGE, 2nd ed., 2009)

14. Social Science Statistics, https://www.socscistatistics.com/

15. National Statistical Institute, www.nsi.bg 